\section{Raking over the coals}

\section{Lee Loevinger}

Sclence, Ideology, and the Media: The Cyrll Burt Scandal. By Ronald Fletcher. Transaction Publishers: 1991. Pp. 419. $\$ 29.95$, £21.95.

A LEGEND of modern science is the Cyril Burt scandal - an eminent scientist posthumously charged with fabricating data. Ronald Fletcher now says the charge is untrue: a spurious product of politics and publicity intruding into science.

Burt (1883-1971) was a pioneer in quantifying psychology, studying individual differences and mental testing. Knighted and the recipient of many other honours during his lifetime, he was described in a Times obituary as "Britain's most eminent educational psychologist". He also believed that intelligence was largely, although not entirely, determined by heredity, a position supported by several papers reporting kinship correlations of intelligence, the most significant of which involved monozygotic twins separated at birth or soon thereafter and raised in different environments.

Strongly opposed to Burt's position were those who contended that mental abilities were environmentally determined, that IQ tests and other hereditarian data were unreliable, and that there really was no single trait identifiable as intelligence. The most vehement environmentalists were left-wing egalitarians who accused Burt of justifying class distinctions.

The first published criticism of Burt's kinship correlations was by Arthur Jensen, who noted 20 pairs of invariant correlations for samples of varying sizes in Burt's publications. In 1974, Leon Kamin wrote a slim volume entitled The Science and Politics of $I Q$ (Erlbaum) in which he attacked Burt's data, arguing that IQs are never free of policy implications and ideology. Criticism of Burt erupted into scandal on 24 October 1976 when Oliver Gillie, medical correspondent of the Sunday Times, published an article beginning: "The most sensational charge of scientific fraud this century is being levelled

\section{New in paperback}

Harvard University Press have recently published Night Thoughts of a Classical Physicist by Russell McCormmach. This fascinating experiment in historiography is a portrait of a composite physicist, a man who never existed but whose career, outlook and activities are based upon those who did. Price is $£ 7.95$. Cell Communication in Health and Disease edited by Howard Rasmussen is an addition to the series 'Readings from Scientific American'. The collection of essays surveys our understanding of cellular signalling, second messengers and signal transduction. Publisher is Freeman, price is $£ 10.95, \$ 13.95$. against the late Sir Cyril Burt”. Gillie charged that Burt's correlations were based on fabricated data and that two women Burt claimed as assistants in gathering data never existed.

The controversy simmered until 1979 when L. S. Hearnshaw published a biography of Burt (Cyril Burt: Psychologist, Cornell University Press, 1979) in which he observed that Burt was "anathema to leftwing egalitarian critics" and that Kamin was biased and captious, but found Burt guilty of fabricating data on monozygotic twins. Hearnshaw credited Burt with being an imaginative pioneer who contributed to psychology but said that his failings were due to a "marginally paranoid condition". The Hearnshaw biography established the fraud charge for all journalists and most scientists. Thus the legend began.

In 1989, Robert Joynson, in a book entitled The Burt Affair (Routledge, 1989) concluded that Hearnshaw's sources did not support the charges and that Burt's work was more credible than that of his critics (for review see Nature 340, 439; 1989). In Science, Ideology, and the Media, Ronald Fletcher presents an even more exhaustive array of evidence to conclude that Burt's only deception was publishing papers he wrote under the name of an assistant. Fletcher is deliberately legalistic, writing as counsel for the defence with cross-examination questions for each of Burt's critics. This approach is a dubious literary device, but Fletcher is right in treating the controversy as similar to common litigation: his marshalling of evidence is sufficient to persuade a lawyer with substantial trial experience and a degree in psychology that his conclusions are correct.

It is apparent that the fraud charge rests entirely on circumstantial evidence, mainly the great improbability of invariant correlations being found in a series of enlarging samples. But to draw a valid inference from circumstantial evidence, it is necessary to consider all the circumstances, and Fletcher presents many that Burt adversaries have ignored.

The invariant data appear in papers published up to 1966, five years before Burt's death, but the fraud charges were not made until five years after his death, and then by a journalist seeking a sensational story. The charge of nonexistence of lady assistants, featured in Gillie's story, is disproved both by the testimony of those who knew the women and by written records. Cartons containing some of Burt's accumulated data, which might have provided direct evidence concerning assailed correlations, were destroyed shortly after his death by Burt's secretary on the advice of Liam Hudson, one of Burt's vehement adversaries.

The crux of Kamin's attack, underlying Gillie's story, was that in 1943 Burt reported 15 pairs of separated monozygotic twins with an IQ correlation of 0.77 . In a 1955 paper, the sample size was 21 and the correlation was 0.771 . In a 1958 paper, the sample size had risen to 'over 30' and the correlation was 0.771 ; and in the 1966 paper the sample size was 53 and the correlation was again 0.771 . But Kamin himself was careless. There was no separate 1958 report of data. The 1958 paper was the publication of a lecture by Burt delivered in 1957 in which he reproduced the entire table of figures published in 1955, and then went on to say that by 1957 he had additional cases of monozygotic twins bringing the total to over 30 .

On the basis of a detailed analysis, Fletcher finds the only suspicious invariant correlation to be the repetition in 1966 of 0.771 first found in 1955. But in 1966, Burt was 82 years old, with declining powers of concentration, doing all his calculations by hand, and writing in haste to reply to other articles. Because the increasing sample sizes were cumulative additions, it is more plausible to suppose that Burt added additional cases to his collection without bothering to calculate new correlations than it is to conjecture that the longtime editor of the British Journal of Statistical Psychology would stupidly fabricate improbably invariant correlations in an effort to deceive other experts. That Hearnshaw was forced to concoct a speculative psychopathology to make such a fraud charge credible shows the weakness of the charge, which appears even more bizarre as Hearnshaw relied mainly on Burt's "mixed ancestry" - part Saxon and part Celtic.

It is relevant that several subsequent independent studies gave the same results as those of Burt. (The most recent, the Minnesota Twin Study, was published in Science, 12 October 1991, too late for inclusion in Fletcher's book.) Also important is a 1972 statement by 50 eminent scientists, including several Nobel laureates, praising Burt's posthumous Thorndike award article for drawing attention to the great influence of heredity in human behaviour. The statement praised Burt's courage because scientists were suffering suppression, censure, punishment and defamation for emphasizing the role of heredity, although such influences are well documented. Unfortunately, this situation continues.

A fair appraisal of all the circumstantial evidence presented by Fletcher compels the conclusion that Burt was eccentric and sometimes careless, but was guilty of heresy rather than fraud. Fletcher is also warranted in asserting that the issues in the Burt case go beyond the vindication of an individual and show the danger of the intrusion of politics into science in skewing or suppressing research results. Fletcher's legalistic style is not ingratiating, but for those concerned with psychology or with the integrity of science this is an important and persuasive book.

Lee Loevinger is at Hogan \& Hartson, 555 Thirteenth Street NW, Washington DC 20004, USA. 